\title{
RETRACTED ARTICLE: Mortality trends in patients with and without diabetes in Ontario, Canada and the UK from 1996 to 2009: a population-based study
}

\author{
M. Lind • L. A. Garcia-Rodriguez • G. L. Booth • \\ L. Cea-Soriano • B. R. Shah • G. Ekeroth • L. L. Lipscombe
}

Received: 26 November 2012 / Accepted: 29 April 2013 / Published online: 22 June 2013

(C) Springer-Verlag Berlin Heidelberg 2013

The authors wish to retract this article, published online on 22 June 2013, because a calculation error has become apparent. Some of the data in Table 2 and ESM Tables 4 and 5 are incorrect, as are some of the secondary conclusions. The authors regret this error and confirm that the main conclusion remains valid.

The authors wish to retract this article, published online on 22 June 2013, because a calculation error has become apparent. Some of the data in Table 2 and ESM Tables 4 and 5 are incorrect, as are some of the secondary conclusions. The authors regret this error and confirm that the main conclusion remains valid. This retraction is intended to maintain the integrity of material published in Diabetologia and the journal acknowledges the full cooperation of the authors. A corrected version of the paper is available at: DOI 10.1007/s00125-013-3063-1.

\section{Lind}

Department of Molecular and Clinical Medicine, Institute of Medicine, Sahlgrenska Academy, University of Gothenburg, Gothenburg, Sweden

\section{Lind $(\bowtie)$}

Department of Medicine, Uddevalla Hospital,

45180 Uddevalla, Sweden

e-mail: lind.marcus@telia.com

L. A. Garcia-Rodriguez $•$ L. Cea-Soriano Spanish Centre for Pharmacoepidemiologic Research (CEIFE), Madrid, Spain
This retraction is intended to maintain the integrity of material published in Diabetologia and the journal acknowledges the full cooperation of the authors.

A corrected version of the paper is available at: DOI 10.1007/s00125-013-3063-1.

G. L. Booth

Li Ka Shing Knowledge Institute of St Michael's Hospital,

Toronto, ON, Canada

B. R. Shah

Sunnybrook Health Sciences Centre, Toronto, ON, Canada

G. Ekeroth

Statistiska Konsultgruppen, Gothenburg, Sweden

L. L. Lipscombe

Women's College Research Institute, Women's College Hospital, University of Toronto, Toronto, ON, Canada 